\title{
Exposure to Intimate Partner Violence: Perceived Links with Other Victimizations and the Severity of Violence by Young Adults in Québec
}

\author{
Geneviève Lessard' ${ }^{1}$, Annie Dumont ${ }^{2}$, Pamela Alvarez-Lizotte ${ }^{1}$, Sophie M. Bisson ${ }^{1}$, \\ Chantal Bourassa ${ }^{3}$, Valérie Roy ${ }^{1}$
}

${ }^{1}$ School of Social Work and Criminology, Laval University, Québec, Canada

${ }^{2}$ Psychoeducation Department, Sherbrooke University, Sherbrooke, Canada

${ }^{3}$ School of Social Work, Moncton University, New Brunswick, Canada

Email: genevieve.lessard@tsc.ulaval.ca

How to cite this paper: Lessard, G., Dumont, A., Alvarez-Lizotte, P., Bisson, S. M., Bourassa, C., \& Roy, V. (2021). Exposure to Intimate Partner Violence: Perceived Links with Other Victimizations and the Severity of Violence by Young Adults in Québec. Open Journal of Social Sciences, 9, 86-106. https://doi.org/10.4236/jss.2021.96009

Received: May 14, 2021

Accepted: June 13, 2021

Published: June 16, 2021

Copyright $\odot 2021$ by author(s) and Scientific Research Publishing Inc. This work is licensed under the Creative Commons Attribution International License (CC BY 4.0).

http://creativecommons.org/licenses/by/4.0/

(c) (i) Open Access

\begin{abstract}
The objective of this qualitative study was to understand how young adults (18 - 25 years old) who were exposed to intimate partner violence (IPV) during childhood and adolescence explained the links between this violence and the other victimizations that they had experienced, as well as the perceived severity that they assigned to these victimizations. The participants $(\mathrm{N}=45)$ were recruited in the Province of Quebec (Canada). Before the interview, they filled out an online questionnaire with the Adult Retrospective Version of the Juvenile Victimization Questionnaire as well as answering sociodemographic questions. They likewise noted the victimization to which they were subjected before they reached adulthood. These data helped us to better prepare the qualitative interviews, allowing us to explore the links the youth see or do not see between their exposure to IPV and other declared victimizations. Interviews lasted an average of two hours and were supported by a semi-structured interview guide and a life history calendar. The results show that many of the participants identified stronger links between exposure to IPV and child maltreatment, intimidation at school, and dating violence. Findings highlight the importance of considering youth's viewpoints about the victimizations they suffer so as to develop intervention and prevention programs that are better adapted to these youth's experiences and point of views.
\end{abstract}

\section{Keywords}

Exposure to Intimate Partner Violence, Child Victimizations, Perceived Links between Victimizations, Perceived Severity of Violence, Qualitative Study 


\section{Introduction}

Intimate partner violence (IPV) is a social problem acknowledged around the world for its high prevalence and major impact on the health of its victims (World Health Organization, 2017). IPV refers to any situation in which an intimate partner exercises coercive control through physical, psychological, sexual, or economic violence against the other partner (Quebec Government, 2018). Police statistics indicate that the majority of the victims are women (Public Security Ministry, 2017), but children who are exposed to this violence are also greatly affected. While the nature of the consequences varies from one child to another, depending on various risk and protection factors, IPV can particularly affect children's physical and mental health, their overall development (physical, cognitive, educational, identity), social skills and functioning (Camacho et al., 2012; Evans et al., 2008; Kitzmann et al., 2003; Wolfe et al., 2003). Although the co-occurrence rates between IPV exposure and other victimizations happening in the family, school or community are well-documented (Clément et al., 2019; Finkelhor et al., 2011; Hamby et al., 2011; Wolfe et al., 2003), the subjective viewpoints of young people on the links between these types of violence and their relative influence on the youth's life course remain unknown. This qualitative study, conducted with young adults from Quebec (Canada) who were exposed to IPV in childhood and adolescence, helps to fill this knowledge gap. The objectives were as follows: 1) draw up a portrait of the victimizations experienced by young people during their childhood and adolescence; 2) explore the viewpoints of youth concerning the relationships they perceive between these victimizations and about the severity they assigned to these victimizations.

\subsection{Prevalence of Exposure to Intimate Partner Violence}

In the United States, $17.9 \%$ of young people under 18 have been exposed to IPV (Hamby et al., 2011). In Canada, 26\% of young adults studying at university say they were affected by this problem during their childhood (Straus \& Michel-Smith, 2014). A more recent portrait in the Province of Québec (Canada) showed that $7 \%$ of children had been exposed to IPV perpetrated against their mother during the preceding twelve months (Clément et al., 2019). The available population and clinical statistics show that exposure to IPV is a widespread problem and that it is one of the most common forms of maltreatment that child protection services have to deal with (Clément et al., 2019; Hélie et al., 2017).

\subsection{Co-Occurrence of Intimate Partner Violence and Other Victimizations}

Exposure to IPV rarely occurs in isolation and is often accompanied by other adversity experiences and forms of victimization. Studies have shown particularly high rates of co-occurrence between exposure to IPV, child maltreatment, and several forms of victimization (Clément et al., 2019; Finkelhor et al., 2011). For children exposed to IPV, the risk of being maltreated or exposed to another 
form of family violence is 3 to 9 times higher than for children who have not witnessed IPV (Hamby et al., 2010). We also know that the development of young people who undergo multiple victimizations is more negatively affected (Aho et al., 2016; Cater et al., 2014; Finkelhor et al., 2011; Wolfe et al., 2003).

Given that certain forms of victimization can increase the risk of experiencing other forms of violence during both childhood and adulthood (Aakvaag et al., 2017), it is essential to examine the complex relationships between the diverse forms of victimization that children are subjected to. Indeed, studying one type of victimization without considering other types prevents us from identifying the specific, distinguishing, and cumulative effects of the different victimizations (Elliot et al., 2009; Finkelhor et al., 2005). It is also important that we better understand the viewpoints of the people directly concerned. For example, the study of Aisenberg et al. (2008) showed that the perception of the severity of the violence one person has been exposed to in his or her community can differ from its objective analysis. In fact, the perception of the severity of the violence can vary based on different variables, such as the type of violence (physical, psychological, etc.), the timing of the victimization (childhood or adulthood), the context of the victimization (family, workplace, etc.), the frequency of the victimization, the fear felt, and so on (Neill et al., 2014; Scott-Storey et al., 2020). It is important to develop this type of knowledge since it can guide professionals with regard to the help they offer to young people exposed to IPV and other victimizations.

Finkelhor et al. (2005) contributed to the development of an important field of knowledge on polyvictimization. Studies that document life-long polyvictimization among adult populations generally employ a definition based on the presence of different types of victimization throughout one's life course, including exposure to IPV (Elliot et al., 2009). A study by Hamby et al. (2010) showed that exposure to IPV is associated with many victimizations, even the non-family forms such as property crime and internet harassment, which suggests that the analysis of exposure to IPV requires a broader view extending beyond experiences that are solely family-based. Moreover, a longitudinal study with a control group conducted with 896 participants who were followed from their childhood for a period of 40 years (Widom et al., 2007) showed the particularly harmful impact of relationship trauma on the risk of revictimization. Relationship trauma refers to violence exercised by a parent or family member-which is the case in exposure to IPV-as opposed to other traumatic events which do not entail a family relationship with the aggressor (for example, property crime, accidents, natural disasters). Youth victims of the former type of violence are more at risk of being revictimized, particularly in their romantic relationships (Widom et al., 2007). A possible explanation for this increased risk of revictimization among young people who have been exposed to IPV could, based on the results of another longitudinal study (Ehrensaft et al., 2011), stem from the consequences of violence, which affects among other things, emotional regulation capacity, thereby making young people more vulnerable in their future relation- 
ships (Ehrensaft et al., 2011). These results point to the importance of taking into consideration the complex relationships between exposure to IPV and the other forms of victimization in the life course of these concerned youth.

\section{Theoretical Framework and Objectives}

Informed by the life course theory (Elder et al., 2003), the goal of the present study was to document relationships between exposure to IPV and other victimizations in a rarely studied population, that is young adults who were exposed to IPV in their childhood and adolescence (Dumont \& Lessard, 2019). This theoretical framework involves a holistic approach considering the whole life of young people in their different living environments, in particular the family, school, friendship, love, and professional trajectories (Bessin, 2009). These trajectories are marked with experiences (for example the various victimizations experienced), roles and transitions that influence everyone's life course (Elder et al., 2003; Wheaton \& Gotlib, 1997). Similar events or victimizations experienced may have different meanings for different people and the meaning given to an experience may evolve through the life course, because of the agency exercised by people (Hitlin \& Elder Jr., 2007). All humans are in constant evolution and each person's life is interrelated with those of the people in their circle (Gherghel \& Saint-Jacques, 2013; Settersten Jr., 2015). This theoretical framework is then very useful to understand the participants' viewpoints about their own victimizations (including exposure to IPV), about the links they identified between exposure to IPV and other victimizations, and about the severity they assigned to these victimizations during their life course. Their current stage in life, namely emerging adulthood (Arnett, 2011), puts them in a particularly good place for sharing their viewpoints about their exposure to IPV and other victimizations, which was recent enough for some and still ongoing for others.

\section{Methodology}

\subsection{Recruitment Strategies and Sample}

To respond to recommendations made by other authors in the field (Aakvaag et al., 2017; Cater et al., 2014), this study took a qualitative approach that was in keeping with its stated objectives. The research focused on young adults who met the following criteria: 1) identified themselves as having been exposed to IPV during childhood or adolescence, whether the abuser was male or female and 2) were from 18 to 25 years old. Most of retrospective studies in the field of exposure to IPV included adults from early adulthood up into their 60s (ex.: Anderson \& Bang, 2011; Benz, 2010; O’Brien et al., 2013; Suzuki et al., 2008). However, the different stages of life are likely to modulate the participants' experiences and points of view, which reinforces the importance of considering the specificities of early adulthood (Arnett, 2011). No exclusion criteria were applied, but an effort was made to diversify the sample as much as possible based on gender and ethnocultural background. For example, specific invitations were 
made to men when we realized that more women than men were going to participate. Recruitment was conducted in the general population (web ads) and some specific populations such as university or college students (emails to students), or clinical services with the help of organizations who presented the research to their young adult clientele.

The sample included 45 young adults from the Province of Québec: 28 women, 15 men, including one who was identified as female at birth, and 2 people who did not self-identify as male or female or who were wondering about their gender identity. The sample was diversified at the ethno-cultural level, given that 5 participants were born in Europe, 3 in Africa, and 1 in South America. Furthermore, among the 36 participants born in Canada, 10 identified their ethnic origin as being Indigenous, Afro-Caribbean, Maghrebian, European, or Asian. Table 1 presents additional sociodemographic characteristics of the participants.

Table 1. Participants' sociodemographic characteristics $(\mathrm{N}=45)$.

\begin{tabular}{|c|c|c|}
\hline \multicolumn{2}{|r|}{ Characteristics } & \multirow{2}{*}{$\begin{array}{l}\mathrm{n}(\%) \\
6(13)\end{array}$} \\
\hline & $18-19$ years & \\
\hline Age & $20-21$ years & $11(24)$ \\
\hline Age & $22-23$ years & $16(36)$ \\
\hline & $24-25$ years & $12(27)$ \\
\hline \multirow{4}{*}{ Gender identification } & Female & $28(64)$ \\
\hline & Male & $15(33)$ \\
\hline & Non-binary & $1(2)$ \\
\hline & Questioning & $1(2)$ \\
\hline \multirow{3}{*}{ Sexual orientation } & Heterosexual & $32(71)$ \\
\hline & Gay or lesbian & $4(9)$ \\
\hline & Bisexual, pansexual, poly, queer, asexual, questioning ${ }^{a}$ & $9(24)$ \\
\hline \multirow{4}{*}{ Place of birth } & Canada & $36(80)$ \\
\hline & Europe & $5(11)$ \\
\hline & Africa & $3(7)$ \\
\hline & America (other than Canada) & $1(2)$ \\
\hline \multirow{3}{*}{ Ethnic origin ${ }^{b}$} & Quebecker/Canadian & $26(59)$ \\
\hline & Other country & $11(25)$ \\
\hline & Mixed origin & $7(16)$ \\
\hline \multirow{4}{*}{ Main occupation } & School & $38(84)$ \\
\hline & Full-time job & $3(7)$ \\
\hline & Unemployed or work stoppage & $3(7)$ \\
\hline & Full-time mother & $1(2)$ \\
\hline \multirow{4}{*}{$\begin{array}{c}\text { Highest level of education } \\
\text { attained }\end{array}$} & Secondary school diploma & $11(24)$ \\
\hline & Vocational school diploma & $2(4)$ \\
\hline & Cégep diploma ${ }^{c}$ & $22(49)$ \\
\hline & University diploma & $10(22)$ \\
\hline \multirow{5}{*}{ Annual revenue $\mathrm{e}^{\mathrm{b}}$} & Less than $\$ 9999$ & $20(45)$ \\
\hline & $\$ 10,000$ to $\$ 19,999$ & $15(34)$ \\
\hline & $\$ 20,000$ to $\$ 29,000$ & $5(11)$ \\
\hline & $\$ 30,000$ to $\$ 39,000$ & $3(7)$ \\
\hline & $\$ 40,000$ to $\$ 49,000$ & $1(2)$ \\
\hline
\end{tabular}




\begin{tabular}{|c|c|c|}
\hline \multirow{4}{*}{ Living } & With parents (and siblings) & $11(24)$ \\
\hline & With romantic partner (and children) & $12(27)$ \\
\hline & In school residence or roommate(s) & $12(27)$ \\
\hline & Alone & $10(22)$ \\
\hline
\end{tabular}

aThe sexual orientation given here is that which the participants used to define themselves. Some gave more than one sexual orientation, which was accounted for in this category of the table. 'One datum was missing for this sociodemographic information. ${ }^{c}$ CEGEPs are general and vocational colleges unique to the Province of Québec's education system. They offer two types of programs: a two-year pre-university program and a three-year vocational-technical program.

\subsection{Data Collection Methods}

The young adults all participated voluntarily in the study, which comprised two data collection steps. They first answered an online questionnaire, that is a French version of the Adult Retrospective Version of the Juvenile Victimization Questionnaire, ARVJVQ (Elliot et al., 2009). This questionnaire documents 35 types of victimization encountered in childhood and adolescence (that occurred before they reached 18 years old) and grouped into five categories: conventional crimes, child maltreatment, victimization by peers and siblings, sexual victimization, and exposure to various types of violence including IPV (for specific forms of victimization in each category, see Table 2). The answers to the ARVJVQ helped to guide the qualitative interviews and thus ensure that young people's viewpoints were collected for each of the declared victimizations, the perceived links with IPV exposure, and their perceived severity. Questions were added at the end of the questionnaire to document the participants' sociodemographic characteristics. In the days following the completion of the online questionnaire, and after the youth provided their written consent to be contacted for the second step, the interviewer contacted the youth to schedule the time and location of the interview based on the participant's preference. The interview took place at the university in most cases, or in some cases at the participant's home or in a room of the organization that referred the participant.

In this second step, the young adults took part in an approximately two-hour, semi-guided interview. The interview was carried out by a research assistant who had been trained by the head researcher in conducting qualitative interviews and using the data collection tools employed in this project. The interview, which was recorded with the participants' consent, touched on the following themes: 1) the experience of exposure to IPV; 2) the other types of violence encountered and the perceived relationships with exposure to IPV according to each case; 3) the consequences of the encountered violence; and 4) the factors that, in their opinion, had a larger influence on their life course (e.g., significant people, events, victimizations). Furthermore, so as to temporally situate the different events in their life course, the participants were asked to fill out a life history calendar (Nelson, 2010) comprising six distinct trajectories: education, work, family, romance, friendship, and other significant events. This tool helped the participants to recall their autobiographical memories (Yoshihama et al., 2002) and to speak freely about what they thought were the most important aspects 
Table 2. Declared victimizations (ARVJVQ).

\begin{tabular}{|c|c|c|c|c|}
\hline \multirow[b]{2}{*}{ Victimization categories } & \multicolumn{4}{|c|}{ Participants } \\
\hline & $\begin{array}{l}\text { Women (\%) } \\
\quad(\mathrm{n}=28)\end{array}$ & $\begin{array}{c}\text { Men }(\%) \\
(n=15)\end{array}$ & $\begin{array}{c}\text { Non-binary or } \\
\text { in questioning }(\%) \\
(\mathrm{n}=2)\end{array}$ & $\begin{array}{c}\text { Total }(\%) \\
(\mathrm{N}=45)\end{array}$ \\
\hline \multicolumn{5}{|c|}{ Conventional crime } \\
\hline Personal theft & $15(54)$ & $9(60)$ & $2(100)$ & $26(58)$ \\
\hline Robbery & $13(46)$ & $10(67)$ & $2(100)$ & $25(56)$ \\
\hline Vandalism & $12(43)$ & $10(67)$ & $2(100)$ & $24(54)$ \\
\hline Assault with an object & $11(39)$ & $7(47)$ & $2(100)$ & $20(44)$ \\
\hline Assault without an object & $25(89)$ & $13(87)$ & $2(100)$ & $40(89)$ \\
\hline Attempted assault & $11(39)$ & $7(47)$ & $2(100)$ & $20(44)$ \\
\hline Kidnapping & $2(7)$ & $1(7)$ & $0(0)$ & $3(7)$ \\
\hline Bias attack & $3(11)$ & $1(7)$ & $1(50)$ & $5(11)$ \\
\hline Total (at least one type) & $27(96)$ & $15(100)$ & $2(100)$ & $44(98)$ \\
\hline \multicolumn{5}{|c|}{ Child maltreatment } \\
\hline Physical maltreatment & $22(79)$ & $10(67)$ & $2(100)$ & $34(76)$ \\
\hline \multicolumn{5}{|l|}{ Psychological maltreatment } \\
\hline Threat of injury & $11(39)$ & $7(47)$ & $1(50)$ & $19(42)$ \\
\hline Name calling & $24(86)$ & $13(87)$ & $2(100)$ & $39(87)$ \\
\hline Neglect & $6(21)$ & $3(20)$ & $2(100)$ & $10(22)$ \\
\hline Taken, kept, or hidden by a parent & $6(21)$ & $3(20)$ & $2(100)$ & $10(22)$ \\
\hline Total (at least one type) & $26(93)$ & $15(100)$ & $2(100)$ & $43(96)$ \\
\hline \multicolumn{5}{|c|}{ Victimization by peers or siblings } \\
\hline Gang assault & $7(25)$ & $4(27)$ & $0(0)$ & $11(24)$ \\
\hline Peer or sibling assault & $19(68)$ & $12(80)$ & $2(100)$ & $33(73)$ \\
\hline Assault on one's private parts & $4(14)$ & $6(40)$ & $0(0)$ & $10(22)$ \\
\hline \multicolumn{5}{|l|}{ Bullying } \\
\hline Threats of injury & $9(32)$ & $3(20)$ & $2(100)$ & $14(31)$ \\
\hline Chase, grab, and making you do things you didn't want to do & $11(39)$ & $5(33)$ & $1(50)$ & $17(38)$ \\
\hline Name calling & $20(71)$ & $12(80)$ & $2(100)$ & $34(76)$ \\
\hline Physical dating violence & $6(21)$ & $3(20)$ & $0(0)$ & $9(20)$ \\
\hline Total (at least one type) & $27(96)$ & $15(100)$ & $2(100)$ & $44(98)$ \\
\hline \multicolumn{5}{|c|}{ Sexual victimization } \\
\hline Sexual assault by a known adult & $6(21)$ & $1(7)$ & $1(50)$ & $8(18)$ \\
\hline Sexual assault by an unknown adult & $2(7)$ & $2(13)$ & $1(50)$ & $5(11)$ \\
\hline Attempted sexual assault by an adult & $4(14)$ & $1(7)$ & $0(0)$ & $5(11)$ \\
\hline Sexual assault by a peer & $5(18)$ & $2(13)$ & $0(0)$ & $7(16)$ \\
\hline Attempted sexual assault by a peer & $10(36)$ & $1(7)$ & $0(0)$ & $11(24)$ \\
\hline Exhibitionism & $6(21)$ & $6(40)$ & $1(50)$ & $13(29)$ \\
\hline Harassment & $9(32)$ & $3(20)$ & $1(50)$ & $13(29)$ \\
\hline Consensual sexual relationships with an adult & $11(39)$ & $4(27)$ & $1(50)$ & $16(36)$ \\
\hline Total (at least one type) & $22(79)$ & $11(73)$ & $2(100)$ & $35(78)$ \\
\hline \multicolumn{5}{|c|}{ Exposure to violence $^{\mathrm{a}}$} \\
\hline Assault on siblings & $17(61)$ & $6(40)$ & $1(50)$ & $24(53)$ \\
\hline Assault with an object & $6(21)$ & $7(47)$ & $1(50)$ & $14(31)$ \\
\hline Assault without an object & $19(68)$ & $12(80)$ & $1(50)$ & $32(71)$ \\
\hline Burglary of a family household & $6(21)$ & $4(27)$ & $1(50)$ & $11(24)$ \\
\hline Murder of a family member or relative & $2(7)$ & $2(13)$ & $0(0)$ & $4(9)$ \\
\hline Random shooting, terrorism, or riots & $5(18)$ & $4(27)$ & $0(0)$ & $9(20)$ \\
\hline War & $1(4)$ & $3(20)$ & $0(0)$ & $4(9)$ \\
\hline Total (at least one type) & $27(96)$ & $13(87)$ & $1(50)$ & $41(91)$ \\
\hline
\end{tabular}

${ }^{a}$ Excluding indicators for exposure to IPV, since this victimization was experienced by $100 \%$ of the participants (selection criterion). 
while still being guided by the themes in the above-mentioned interview guide. A sum of $\$ 40$ was given to each participant in compensation for their time and travel expenses. A debriefing was conducted at the end of each interview to verify how the participants felt about having shared their intimate experiences. References for psychosocial help services were systematically provided. The project was approved by the research ethics committee of Laval University.

\subsection{Analysis Methods}

The interviews were integrally transcribed and anonymized (pseudonyms are used below). Thematic content analysis (Braun \& Clarke, 2006) was then conducted. Data was codified by two research assistants using NVivo software, then systematically verified by the head researcher for the main codes which served in the production of this article. A grid was developed based on the research objectives and the themes of the interview, leaving room also for themes to emerge from the data, given that the participants were free to talk about other themes that were important to them. This corresponds in qualitative research to a hybrid approach which combines inductive and deductive coding (Fereday \& Muir-Cochrane, 2006). Attention was paid to the relative significance accorded by people to the various victimizations. The victimizations declared in the online questionnaire did not take all the same space in the discourse of the participants, who did not always accord the same degree of severity to all the forms of endured violence. Because of the considerable amount of data, the research assistants produced an abstract ( 2 to 3 pages) of each interview, and also tables including relevant data from all the interviews. In these tables, the data were classified according to the degree of perceived severity of the victimizations experienced. These documents (interview summaries and tables) allowed us to have a qualitative description of the participants' experiences of exposition to IPV (length, types, who committed IPV and who was the victim, perceived severity), of the other victimizations (types, perceived severity), and of the factors identified by the participants concerning the perceived severity of their victimizations. Each statement provided in the tables was supported by participants' quotations. These documents were then discussed by members of the research team to identify the perceived links between victimizations and their severity.

\section{Results}

Since the point in common between the study participants was having been exposed to IPV, we shall begin here by describing their experiences with this type of victimization. This will be followed by a portrait of the other declared types of victimization, and then with a description of the links that these young adults perceived between exposure to IPV and these other victimizations.

\subsection{Exposure to Intimate Partner Violence: Various and Repeated Forms}

A large majority of the participants reported that their father or stepfather 
committed IPV on their mother (75.6\%). In a few situations, the violence was described as being bidirectional $(17.8 \%)$ or directed by the step-mother at the father (6.7\%). Most of the participants were exposed to IPV during all of their childhood and adolescence. They were exposed to physical, verbal, and psychological types of violence. Some of the participants also identified economic or sexual violence. The parents of some participants were still together, and the IPV continued whether or not the participants had left the family home. In cases where the parents had separated, the violence had sometimes stopped and other times continued, either between ex-partners or in a new relationship between a parent and a new partner. A third of the participants were moreover exposed to IPV in more than one family unit. As the next excerpt shows, the study participants did not see IPV as an isolated incident. On the contrary, it lasts over time and follows a repeated cycle of victimizations for the victim parent and children.

He would really blow his top, things would go really bad, and then after, it was a honeymoon. Things would go well for a while, he would show up with sweets, with flowers. (...) few days later, he would start all over again. (Audrey, 24 years old)

The frequency and repetitive nature of the IPV dynamics led some participants, like Mathilde and Samuel, to see their parents' and stepparents' IPV as being substantial and severe. The fact that the parents experienced IPV over a long period of time, as well as the participants' feelings of fear and powerlessness during these IPV episodes also influenced their perception of the family dynamics.

It's been 15 years now we've been carrying it on our shoulders. It's been so frustrating for me. My brothers are stuck in it. They hear my parents fighting, shouting at each other. He treats my mother like, ... oof. I don't understand why my mother stays. (...) And we're still stuck in it. (Mathilde, 23 years old)

She [mother-in-law] was literally being pushed onto the bed. (...) I didn't know what to do. (...) I was frozen, frozen like ice. All I could do was sit there. (Samuel, 25 years old)

For other participants, the realization that IPV is not a normal aspect of family life led them to become aware of the severity of the violence that they were being exposed to. This realization was sometimes facilitated by observing other families or after professional intervention, as explained by Audrey and Béatrice.

I thought what was happening at home was normal. And then one day [after going to a friend's house], I went like "Wow, wait a minute, not everybody's like us." (Audrey, 24 years old).

I think the police arrived, there were four cars, and he fought with the police and all that. We got support, we went to the battered women's shelter. (...) It was serious stuff and, I don't know how to say it, it was really official. After that, I never saw my father again. (Béatrice, 24 years old) 


\subsection{Portrait of Other Victimizations}

The young adults we met with in this study had all experienced several types of victimization in their childhood in addition to exposure to IPV. The following table provides an overall portrait of the victimizations as declared by the participants. The participants reported having experienced an average of 17 types of victimization among those evaluated by the ARVJVQ. The interviews also highlighted the fact that the participants experienced some of the victimizations declared in the questionnaire more than once. The majority $(71 \%, \mathrm{n}=32)$ declared having been subjected to victimizations in all five categories of the ARVJVQ, while all the others suffered victimizations in at least three distinct categories. The most prevalent victimizations were those related to conventional crime, victimization by peers or siblings, and child maltreatment. In fact, almost all participants (98\%, 98\% and 96\%, respectively) declared having been subjected to at least one type of victimization within these three categories. Table 2 also shows that participants of different gender identities declared having been subjected to relatively similar rates of victimizations, except for the category "sexual victimization" and "exposure to violence".

\subsection{Perceived Links and Severity of Victimizations}

The interviews with the participants proved to be particularly useful in furthering our understanding of the meaning these victimizations took on for them. Indeed, the same type of victimization will not always have the same meaning, importance, or perceived severity in these young people's life course. Some reported violence so intense that they feared for their lives (e.g., "At one point, I was afraid they would kill me [bullying at school]”, Mathilde, 23 years old). Furthermore, intense violence had serious consequences on their ability to adapt in their life course. Others considered that some of the types of violence they were subjected to were less serious. They explained their perception of the gravity of violence as regards the tendency to trivialize or normalize violence that has been repeatedly endured (for example, "It happened regularly, with cooking utensils, the small [... laughter], I'm laughing because it's cultural, the small wooden spoon that you cook with, oh là là, my mother broke many of those on our backs [laughter]" (Carole, 20 years old). The perception of the severity of the violence sometimes varied over time, with some types of violence becoming more important for young people as they grew up and realized that it wasn't normal or acceptable to be subjected to such violence, as explained by Annabelle.

There were types of behaviour from my third boyfriend that I think I accepted because I'd already seen them with [father's first name]. (...) I was a bit vaccinated because I'd seen it so often with my dad during my childhood that afterwards, in a relationship, I didn't know anymore if it was normal or unacceptable. (...) It was especially with him [third boyfriend] when he started putting me outside in the middle of the night. (...) It was stuff worse than what my father did. Like putting me outside, [father's first 
name] never did that. Or locking me inside a car (...). (Annabelle, 19 years old)

Our analysis indicated closer links between exposure to IPV and three other forms of victimization, namely: child maltreatment by the parents (against the participants or their siblings), intimidation by peers, and dating violence. Some of the other types of victimization endured were recounted in conjunction with an event involving one of these three forms. While the first two (maltreatment and intimidation) stood out as being more frequent (see Table 2), the study participants also established close ties between exposure to IPV and dating violence, which was nonetheless experienced less often by the participants. As concerns dating violence, the participants described physical, sexual, verbal, and psychological violence, in particular coercive control. Moreover, the participants also noticed certainties between the violence they were subjected to and those they self-inflicted or reproduced on others. The links they perceived are explained below based on the participants' viewpoints and experiences.

For many participants, the exposure to IPV and the direct victimization that their parents subjected them to were inseparable, even though they adopted several ways of explaining these links in their comments. Three main explanations came out of the interview analysis. First, some participants, like Fathima, explained that IPV and maltreatment of children could happen in the same event. They spoke of situations in which the IPV triggered a spillover effect which finished up by reaching them, particularly when they tried to bring the IPV to an end. The second explanation of the close ties between IPV and violence towards children resided in the fact that child maltreatment also engendered IPV when, for example, a parent (in the example below, Elias' mother) tried to defend the children from the violence of the other parent (Elias' father). Third, child maltreatment, such as the situation reported by Carole, also became an IPV tool used by the aggressor to make the other parent suffer; this involvement in the IPV dynamics increased some participants' perception of the violence's severity.

Even when I was trying to help them, they turned on me. Like I was in their field of vision, so they joined up on me. (Fathima, 18 years old)

Everybody could be attacked (...). If someone tried to defend somebody else, (...) they were automatically going to get it [violence] (...). My mother was almost always getting it (...), because she was always trying to defend somebody. (Elias, 21 years old)

Each time there was something wrong between my parents, my father would use us to get revenge, because he knew my mother loved us more than anything else. So, when he wanted to hurt her, he would hurt us. (Carole, 20 years old)

The inaction of the non-maltreating parent and the presence or severity of the maltreatment inflicted on the child or adolescent influenced some of the participants' perceptions of the severity of the violence that they were subjected to. 
The relationship between [father's name] and his girlfriend [was very difficult for us]. (...) cause she wasn't very nice with us, and she was really hard to get along with. Our father didn't defend us, he just let it go, and that really ruined our self-confidence. (Annabelle, 19 years old)

The role of the young people in the family dynamics and the strategies they used sometimes accentuated their victimization. For example, when they chose like Rachel to confront the aggressor, this would sometimes decrease the violence aimed directly at them, even though the exposure to violence directed at their siblings and mother continued. In this regard, Audrey explained that her role as a barometer and pacifier in the family-that is, her ability to detect tension, the risk of violence and, consequently, to adapt her behaviour-meant that her father attacked her less often than he did her mother or brother.

I thought “There's no way I'll let him treat me like that, I'm not going to live in a permanent state of fear" (...). I confronted him, and he didn't like it (...) he would get even angrier. (Rachel, 21 years old)

I could read him, so when I saw that he was going to blow his top, I would give my brother and mother a kick under the table to tell them to shut up and stop talking so that he wouldn't explode. But I was the only one who could read him and know exactly when he was going to lose it. (Audrey, 24 years old)

One element in the interviews that sheds light on the relationships between exposure to IPV and the other forms of victimization and that explains how, in certain cases, people can stay in a violent relationship, resides in the desensitization that exposure to IPV causes. Indeed, by being exposed to violence, young people can start believing that it is normal to tolerate it when you love someone, as noted by Mathilde. Moreover, participants like Charlotte who experienced both exposure to IPV and violence in their own dating relationships explained how the accumulation of victimizations affected their ability to trust people and stand up for themselves in these relationships.

He was my first boyfriend. He was the first guy I ever loved. (...) I saw my stepfather speak [violently] like that to my mother (...). I thought maybe it was normal to put up with that when you love someone. (Mathilde, 23 years old)

I was always afraid of not being good enough, and my ex made me feel like that even more. When I was with him, I would see my mother and think "Damn, my whole life I told her I'd never accept that, I promised her." And now I'm stuck in the middle of it, can't get out. (Charlotte, 21 years old)

The relation between exposure to IPV and dating violence would seem to be based on a perception of an unequal power relationship: "the violence I experienced with my father resembles the one I went through with my ex. Like I was explaining, it's all in the voice, 'I'm the one who dominates'." (Alexandra, 21 years old). While, for several participants, the fact of having experienced these 
two types of victimization made their adjustment more difficult, in certain situations, violence in their dating relationship pushed them to make changes when the chosen strategy was to stand up and refuse the violence. Indeed, an initial victimization experience in a dating relationship sometimes led the person to more clearly identify with the experiences of the IPV-victim parent (often the mother) to which she had been exposed for a long time. This awareness at times provoked a strong refusal of this new victimization experience and led to concrete action to get out of a violent relationship.

I kept seeing myself as my mother. "There's no good reason to stay." That's when I really stepped back and said, "Shit, I've become my mother, I'm in the same situation as her, I have to leave." I just took my things and left [my ex-boyfriend]. I found myself another apartment. (Nathan, 22 years old)

The impact of victimization within the family affects not only intimate relationships, but also relationships between peers and with oneself. Participants like Mathilde explained that the consequences of the violence they were subjected to at home left them more vulnerable to bullying at school. They described themselves as easy targets because they were more isolated and had difficulty making friends. This internalizing of difficulties also led, in cases such as Annabelle's, to self-harm, which was explained as the consequence of an accumulation of various victimizations and difficult experiences. In other cases, violence was reproduced against other people, as explained by Christian.

I was really nervous. I was scared of almost everything. I started school almost at the same time. (...) When you are withdrawn and don't talk with other people and don't really care, well you become a target (Mathilde, 23 years old).

I wasn't really a person who fought a lot, but I built up a lot of frustration, and I think violence became like a personal problem for me. Like my anorexia, it was a kind of self-mutilation. (Annabelle, 19 years old)

[Inflicted violence], it's sad to say but it's true, there was quite a bit. (...) I hit a guy because I thought he said something about me. (Christian, 25 years old)

\section{Discussion}

This study is in keeping with other studies that have previously shown relationships between different types of victimization (Clément et al., 2019; Finkelhor et al., 2011). The results of the present study further our knowledge by providing a deeper understanding of the relationships between these types of victimization based on the viewpoints of the people directly concerned, that is, the young adults (18 - 25 years old) who have been exposed to IPV in their childhood or adolescence. As the links between certain types of victimization have already been quantitatively documented, the present study's original contribution consists in the explanation of the process underlying these links and of the perceived 
severity of the different forms of violence endured by these young people in their life course.

The life course of the youth in this study having been interspersed with numerous victimizations, there was a mean of 17 victimizations declared for the 35 measured by the ARVJVQ, some of which were repeated several times. However, these young adults did not attribute the same importance to the various victimizations in their life course. Some types of violence and their related characteristics (i.e., frequency, intensity, length of time, fear and powerlessness, presence and severity of related consequences, youth's involvement in IPV, and perceived abnormality of the violence) were described as having had a more severe impact, whereas others had little or no place in their discourse. Studies that have looked at the perception of the severity of violence also show different characteristics associated with the violence, the context of the violence, and the emotions that play a role in how they perceived it (Neill et al., 2014; Scott-Storey et al., 2020). Informed by the youths' explanation of the strong links they perceived between IPV exposure and certain victimizations, the present discussion puts forward recommendations for future research and interventions.

As concerns the links that the participants made between exposure to IPV and child maltreatment, they gave three main explanations, namely: 1) child maltreatment as a consequence of IPV, 2) maltreatment as a strategy used by the perpetrator of the violence in the couple relationship, and 3) IPV as a consequence of maltreatment. Some of these links, in particular the first two, were observed more than 20 years ago in a meta-analysis by Appel and Holden (1998), but since then, very few studies have explored the complex relationships between IPV and child maltreatment from the qualitative viewpoint of the young people directly concerned, apart from studies of the roles and strategies of children exposed to IPV (Goldblatt \& Eisikovits, 2005; Paradis, 2012). For example, as concerns the first explanation, studies have shown that if children feel they have caused the IPV or if they have been parentified, that is to say, if they take on the responsibilities that are normally those of a parent, this increases the risk that they will have internalizing or externalizing disorders (Fortin et al., 2011). When children feel they need to intervene to make IPV stop, they are more at risk of having the violence aimed directly at them, which was also reported by our respondents who talked of maltreatment as a consequence of IPV. This overflow of violence between intimate partners onto the rest of the family has also been noted by other authors (Schields \& Cicchetti, 2001). In some situations however, when the people confront the aggressor, it can lead to a decrease in violence against them, even though it is often redirected towards other family members, as our respondents explained.

Another important element to highlight so as to better understand the links between IPV and maltreatment was the power dynamics which were identified by some young people in the relationship between their parents. The official definitions of IPV, such as that of the Government of Québec (2018), often insist moreover on the unequal power dynamics between men and women in society 
as a factor likely to give rise to IPV. The violence perpetrator exercises control not only on the other parent but also on the children and all the family members. This analysis may support the young people's second and third explanations according to which the children were used by the father to hurt the mother, or the father committed violence on the mother because she tried to defend the children from the father. Other studies have shown that children can be used by the violence perpetrator to hurt the other parent, particularly after separation (Zeoli et al., 2013) and that mothers develop strategies to try and protect their children from violence (Bohrman et al., 2017). Several IPV situations were described by the study participants as violence by the father or stepfather against the mother. Nonetheless, the dynamics of bidirectional IPV or those where the father is attacked by the stepmother are not as well explained in the theoretical definitions generally given for IPV. Other studies are thus necessary if we are to compare different exposures to IPV experiences, improve our analysis models, and deepen our understanding so as to better describe the diversity of exposure to IPV.

As concerns the relationship between exposure to IPV and victimizations that occurred outside the family circle, our study results are in keeping with other studies that have shown that exposure to IPV increases the probability of encountering violence in future romantic (Kaufman-Parks et al., 2018) or peer relationships (Knous-Westfall et al., 2011). While our study cannot quantitatively measure the degree of association between victimizations, it offers an enriched understanding of the links that are seen to be important by the concerned youth. The explanations put forward by the young adults that we met centred on a normalization of violence and a difficulty in trusting people and in asserting themselves, which resulted from their exposure to IPV. Indeed, children exposed to IPV carry a dark family secret and are more socially isolated (Goldblatt \& Eisikovits, 2005; Paradis, 2012), which makes them more vulnerable to bullying by their peers. This emphasizes the importance of creating, at schools or in other places frequented by young people, more prevention strategies and activities that will help children exposed to IPV to break their isolation, to improve their self-esteem, and to retake control of their lives. This was suggested by Stapleton et al. (2010), who recommended to create activities that provide "a diversion, both in keeping their minds off exposure and literally providing a space that was free of the violence that was happening at home" (p.18).

Barnes et al. (2016) showed furthermore that the fact of having been exposed to polyvictimization during childhood is associated with a lack of social support among young adults. Interventions such as these are vital for reinforcing the social support network (Paradis, 2012), which is an essential protection factor. Services for young people exposed to IPV are not yet making great enough use of this protection factor, which could be used to safeguard them from revictimization and help them to gain more control of their lives.

Even though awareness campaigns are primarily conducted for adults and violence prevention programs are for the most part offered for young people in 
schools, exposure to IPV and its consequences are rarely discussed with children in the general population (Dumont et al., 2012). The fact that some of the young people we met in this study had to suffer another victimization in their own dating relationship before realizing the unacceptable nature of IPV bears witness to the lack of prevention programs. These programs cannot of course protect young people from all types of victimization. Primary prevention with all young people does however have several advantages, whether or not they have been exposed to IPV. For young people who are exposed to IPV, this could help them to more easily and quickly recognize violent relationships, to stand up against this violence, to avoid being perceived as easy targets, and to be more inclined to look for help, in addition to making them more confident about finding healthy and egalitarian relationships. For young people who are not experiencing IPV, these prevention activities could help them to better understand IPV and the importance of providing support for peers who are affected. That said, evaluative research of prevention strategies and research of the ties between victimizations and protection factors are necessary to verify the hypotheses emerging from the present study.

We also consider that improved screening of exposure to IPV and treatment for related consequences are needed. This is all the more important given that the consequences increase when there are other victimizations alongside exposure to IPV (Aho et al., 2016; Cater et al., 2014; Finkelhor et al., 2011; Wolfe et al., 2003), as is the case with the young people in our study. Due to the lack of an adequate response to the psychological and emotional needs of these young people during their childhood and adolescence, it is possible that their adjustment will be more difficult when they experience exposure to IPV. This is all the more important considering the serious consequences of this lack of support. Indeed, some young people we met for the present study noted that their suffering turned into self-inflicted violence or violence towards others.

Certain studies have shown that girls are victimized more often by their family members and intimate partner, whereas boys encounter more violence among their peers (Cater et al., 2014), in conventional crime, and in community violence (Aho et al., 2016). In the present study, these types of violence were declared by men, women and participants who identified themselves as nonbinary or in questioning as indicated in Table 2. While comparative gender analysis was not the goal of the present study, the descriptive results nonetheless raise important questions for future research. It is possible that the highly homogeneous nature of our sample (all of them had been exposed to IPV) explains why the gender difference identified in other studies does not seem to emerge in the same way in our study. However, we can also ask whether the presence of IPV constituted a mediating factor which contributed, for some of the other victimizations, to minimize gender differences or, for others, to accentuate them. While this question cannot be answered with the methodology employed in the present study, it nonetheless remains pertinent for future research. 
In short, this study has some limitations worth noting. Although the sample size was appropriate for a qualitative analysis and allowed us to attain data saturation (Ouellet \& Saint-Jacques, 2000), it is possible that the young people who volunteered to participate in the study had made enough personal progress so as to be able to talk about their experiences. Consequently, their viewpoints may not necessarily be applicable to all young adults with IPV exposure. Were the participants among the most resilient young people who had been exposed to IPV? We were not able to answer this question. Moreover, as they had experienced a large number of diverse victimizations, this sample would seem to adequately reflect what other studies have reported about young people with IPV exposure.

\section{Conclusion}

The results of this qualitative study, conducted with 45 young adults (18 - 25 years old), help us to better understand the relationships between exposure to IPV and other victimizations faced by young adults during their childhood and adolescence. As the study results show, the young adults who were directly concerned by this problem were well-suited for sharing their viewpoints on the subject. During the interviews, they especially talked about the links between exposure to IPV and three types of victimization, that is child maltreatment, intimidation at school, and dating violence, with which they perceived as more important links. Concerning the perceived severity of their victimizations, they identified different characteristics (i.e., frequency, intensity, length of time, fear and powerlessness, presence and severity of related consequences, youth's involvement in IPV, and perceived abnormality of the violence) as having had a more severe impact on their experience. Also, their views of their IPV exposure and the perceived links with other victimizations were very helpful in understanding how intervention and prevention programs could be better adapted to the experiences of young people who have been exposed to IPV. However, because the goal of this study was to examine the relationships between exposure to IPV and the other victimizations, other important themes were left aside, in particular the development of significant relationships with other people in the participants' lives. We think it would be important for future research to further our knowledge on this theme given that other studies have shown that IPV affects the quality of the parent-child relationship, even in the long term when the child has become an adult (Buchanan et al., 2015; Liu et al., 2017). One might also ask how the relationships that these youth have with people from other areas in their lives can influence their exposure to IPV and other victimizations. When they are positive, can these relationships protect young people from other victimizations? And what about the relationship with the IPV perpetrator or with the perpetrators of other victimizations that they were subjected to throughout their life course? All these questions indicate the importance of pursuing research that takes into account several victimizations and the importance that young people 
attach to these victimizations over their life course.

\section{Acknowledgements}

This research was made possible through a grant from the Social Sciences and Humanities Research Council (SSHRC) of Canada. The authors also wish to thank Rémi Bilodeau and Valérie Meunier (à coeur d'homme-Réseau d'aide pour une société sans violence), Karine Demers (Violence Info), and Simon Lapierre (University of Ottawa) for their contributions and their involvement in other scientific productions resulting from the project.

\section{Conflicts of Interest}

The authors declare no conflicts of interest regarding the publication of this paper.

\section{References}

Aakvaag, H. F., Thoresen, S., Wentzel-Larsen, T., \& Dyb, G. (2017). Adult Victimization in Female Survivors of Childhood Violence and Abuse: The Contribution of Multiple Types of Violence. Violence against Women, 23, 1601-1619. https://doi.org/10.1177/1077801216664427

Aho, N., Proczkowska-Bjorklund, M., \& Goran Svedin, C. G. (2016). Victimization, Polyvictimization, and Health in Swedish Adolescents. Adolescent Health, Medicine and Therapeutics, 7, 89-99. https://doi.org/10.2147/AHMT.S109587

Aisenberg, E., Ayon, C., \& Orozco-Figueroa, A. (2008). The Role of Young Adolescents' Perception in Understanding the Severity of Exposure to Community Violence and PTSD. Journal of Interpersonal Violence, 23, 1555-1578.

https://doi.org/10.1177/0886260508314318

Anderson, K. M., \& Bang, E.-J. (2011). Assessing PTSD and Resilience for Females who During Childhood Were Exposed to Domestic Violence. Child \& Family Social Work, 17, 55-65. https://doi.org/10.1111/j.1365-2206.2011.00772.x

Appel, A. E., \& Holden, G. W. (1998). The Co-Occurence of Spouse and Physical Child Abuse: A Review and Appraisal. Journal of Family Psychology, 12, 578-599. https://doi.org/10.1037/0893-3200.12.4.578

Arnett, J. J. (2011). Bridging Cultural and Developmental Approaches to Psychology: New Syntheses in Theory, Research, and Policy. Oxford: Oxford University Press.

Barnes, S. E., Howell, K. H., \& Miller-Graff, L. E. (2016). The Relation between Polyvictimization, Emotion Dysregulation, and Social Support among Emerging Adults Victimized during childhood. Journal of Aggression, Maltreatment \& Trauma, 25, 470-486. https://doi.org/10.1080/10926771.2015.1133749

Benz, J. L. (2010). Life Experiences of Adults Who Witnessed Domestic Violence as Children. Ph.D. Thesis, St. Louis, MO: St. Louis University.

Bessin, M. (2009). Parcours de vie et temporalités biographiques: Quelques éléments de problématique. Informations Sociales, 156, 12-21.

https://doi.org/10.3917/inso.156.0012

Bohrman, C., Tennille, J., Levin, K., Rodgers, M., \& Rhodes, K. (2017). Being Superwoman: Low Income Mothers Surviving Problem Drinking and Intimate Partner Violence. Journal of Family Violence, 32, 699-709. 
https://doi.org/10.1007/s10896-017-9932-5

Braun, V., \& Clarke, V. (2006). Using Thematic Analysis in Psychology. Qualitative Research in Psychology, 3, 77-101. https://doi.org/10.1191/1478088706qp063oa

Buchanan, F., Wendt, S., \& Moulding, N. (2015). Growing Up in Domestic Violence: What Does Maternal Protectiveness Mean? Qualitative Social Work, 14, 399-415. https://doi.org/10.1177/1473325014547251

Camacho, K., Ehrensaft, M. K., \& Cohen, P. (2012). Exposure to Intimate Partner Violence, Peer Relations, and Risk for Internalizing Behaviors: A Prospective Longitudinal Study. Journal of Interpersonal Violence, 27, 125-141. https://doi.org/10.1177/0886260511416474

Cater, A. K., Andershed, A.-K., \& Andershed, H. (2014). Youth Victimization in Sweden: Prevalence, Characteristics and Relation to Mental Health and Behavioral Problems in Young Adulthood. Child Abuse \& Neglect, 38, 1290-1302. https://doi.org/10.1016/j.chiabu.2014.03.002

Clément, M.-E., Julien, D., Lévesque, S., \& Flores, J. (2019). La violence familiale dans la vie des enfants du Québec, 2018. Les attitudes parentales et les pratiques familiales. Résultats de la 4e édition de l'enquête. Québec, QC: Institut de la statistique du Québec.

Dumont, A., \& Lessard, G. (2019). Young Adults Exposed to Intimate Partner Violence in Childhood: The Qualitative Meanings of This Experience. Journal of Family Violence, 35, 981-792. https://doi.org/10.1007/s10896-019-00100-Z

Dumont, A., Mathieu, K., Delisle, R., Ménard, J., Paradis, F., St-Hilaire, P., \& Lessard, G. (2012). L'exposition à la violence conjugale: Les défis d'en parler de façon sécuritaire aux enfants. Québec: Table Carrefour Violence Conjugale Québec Métro.

Ehrensaft, M. K., Knous-Westfall, H. M., \& Cohen, P. (2011). Direct and Indirect Transmission of Relationship Functioning across Generations. Journal of Family Psychology, 25, 942-952. https://doi.org/10.1037/a0025606

Elder, G. H. J., Johnson, M. K., \& Crosnoe, R. (2003). The Emergence and Development of Life Course Theory. In J. T. Mortimer, \& M. J. Shanahan (Eds.), Handbook of the Life Course (pp. 3-19). Berlin: Springer. https://doi.org/10.1007/978-0-306-48247-2 1

Elliot, A. N., Alexander, A. A., Pierce, T. W., Aspelmeier, J. E., \& Richmond, J. M. (2009). Childhood Victimization, Poly-Victimization, and Adjustment to College in Women. Child Maltreatment, 14, 330-343. https://doi.org/10.1177/1077559509332262

Evans, S. E., Davies, C., \& Dilillo, D. (2008). Exposure to Domestic Violence: A Meta-Analysis of Child and Adolescent Outcomes. Aggression and Violent Behavior, 13, 131-140. https://doi.org/10.1016/j.avb.2008.02.005

Fereday, J., \& Muir-Cochrane, E. (2006). Demonstrating Rigor Using Thematic Analysis: A Hybrid Approach of Inductive and Deductive Coding and Theme Development. International Journal of Qualitative Methods, 5, 80-92. https://doi.org/10.1177/160940690600500107

Finkelhor, D., Hamby, S. L., Ormrod, R. K., \& Turner, H. A. (2005). The Juvenile Victimization Questionnaire: Reliability, Validity, and National Norms. Child Abuse \& Neglect, 29, 383-412. https://doi.org/10.1016/j.chiabu.2004.11.001

Finkelhor, D., Shattuck, A., Turner, H. A., Ormrod, R., \& Hamby, S. L. (2011). Polyvictimization in Developmental Context. Journal of Child \& Adolescent Trauma, 4, 291-300. https://doi.org/10.1080/19361521.2011.610432

Fortin, A., Doucet, M., \& Damant, D. (2011). Children's Appraisals as Mediators of The Relationship between Domestic Violence and Child Adjustment. Violence and Victims, 26, 377-392. https://doi.org/10.1891/0886-6708.26.3.377 
Gherghel, A., \& Saint-Jacques, M. C. (2013). La théorie du parcours de vie (life course): une approche interdisciplinaire dans l'étude des familles. Québec, QC: Les Presses de l'Université Laval.

Goldblatt, H., \& Eisikovits, Z. (2005). Role Taking of Youths In a Family Context: Adolescents Exposed to Interparental Violence. American Journal of Orthopsychiatry, 75, 644-657. https://doi.org/10.1037/0002-9432.75.4.644

Hamby, S., Finkelhor, D., Turner, H., \& Ormrod, R. (2010). The Overlap of Witnessing Partner Violence with Child Maltreatment and Other Victimizations in a Nationally Representative Survey of Youth. Child Abuse \& Neglect, 34, 734-741. https://doi.org/10.1016/j.chiabu.2010.03.001

Hamby, S., Finkelhor, D., Turner, H., \& Ormrod, R. (2011). Children's Exposure to Intimate Partner Violence and Other Family Violence. Juvenile Justice Bulletin, 10, 1-12. https://doi.org/10.1037/e725322011-001

Hélie, S., Collin-Vézina, D., Turcotte, D., Trocmé. N., \& Girouard, N. (2017). Étude d'incidence québécoise sur les situations évaluées en protection de la jeunesse en 2014 (ÉIQ-2014). Montréal: Ministère de la Santé et des services sociaux.

Hitlin, S., \& Elder Jr., G. H. (2007). Time, Self, and Curiously Abstract Concept of Agency. Sociological Theory, 25, 170-191. https://doi.org/10.1111/j.1467-9558.2007.00303.x

Kaufman-Parks, A. M., DeMaris, A., Giordano, P. C., Manning, W. D., \& Longmore, M. A. (2018). Intimate Partner Violence Perpetration from Adolescence to Young Adulthood: Trajectories and the Role of Familial Factors. Journal of Family Violence, 33, 27-41. https://doi.org/10.1007/s10896-017-9924-5

Kitzmann, K. M., Gaylord, N. K., Holt, A. R., \& Kenny, E. D. (2003). Child Witnesses to Domestic Violence: A Meta-Analytic Review. Journal of Consulting and Clinical Psychology, 71, 339-352. https://doi.org/10.1037/0022-006X.71.2.339

Knous-Westfall, H. M., Ehrensaft, M. K., Watson MacDonell, K., \& Cohen, P. (2011). Parental Intimate Partner Violence, Parenting Practices, and Adolescent Peer Bullying: A Prospective Study. Journal of Child and Family Studies, 21, 754-766. https://doi.org/10.1007/s10826-011-9528-2

Liu, W., Mumford, E. A., \& Taylor, B. G. (2017). The Relationship between Parents' Intimate Partner Victimization and Youths' Adolescent Relationship Abuse. Journal of Youth and Adolescence, 47, 321-333. https://doi.org/10.1007/s10964-017-0733-1

Neill, K. S., Sane-A, R. N., \& Peterson, T. (2014). Perceived Risk, Severity of Abuse, Expectations, and Needs of Women Experiencing Intimate Partner Violence. Journal of Forensic Nursing, 10, 4-12. https://doi.org/10.1097/JFN.0000000000000020

Nelson, I. A. (2010). From Quantitative to Qualitative: Adapting the Life History Calendar Method. Field Methods, 22, 413-428. https://doi.org/10.1177/1525822X10379793

O’Brien, K., Cohen, L., Pooley, J. A., \& Taylor, M. F. (2013). Lifting the Domestic Violence Cloak of Silence: Resilient Australian Women's Reflected Memories of Their Childhood Experiences of Witnessing Domestic Violence. Journal of Family Violence, 28, 95-108. https://doi.org/10.1007/s10896-012-9484-7

Ouellet, F., \& Saint-Jacques, M.-C. (2000). Les techniques d'échantillonnage. In R. Mayer, F. Ouellet, M.-C. Saint-Jacques, \& D. Turcotte (Eds.), Méthodes de recherche en intervention sociale (pp. 71-90). Boucherville, QC: Gaetan Morin.

Paradis, L. (2012). L'enfant, une éponge... L'enfant exposé à la violence conjugale. Son vécu, notre rôle. Québec, QC: Centre intégré universitaire de santé et de services sociaux de la Capitale-Nationale.

Public Security Ministry (2017). Les infractions contre la personne commises dans un 
contexte conjugal au Québec en 2015. Montréal: Quebec Government.

Quebec Government (2018). Government Action Plan on Domestic Violence 2018-2023. Québec, QC: Quebec Government.

Schields, A., \& Cicchetti, D. (2001). Parental Maltreatment and Emotional Dysregulation as Risk Factors for Bullying and Victimization in Middle Childhood. Journal of Clinical Child Psychology, 30, 349-363. https://doi.org/10.1207/S15374424JCCP3003 7

Scott-Storey, K., O’Donneell, S., Wuest, J., MacIntosh, J., \& Merritt-Gray, M. (2020). Cumulative Lifetime Violence Severity Scale: Development and Initial Testing among Men. BMC Public Health, 20, Article No. 418.

https://doi.org/10.1186/s12889-020-08551-6

Settersten Jr., R. A. (2015). Relationships in Time and the Life Course: The Significance of Linked Lives. Research in Human Development, 12, 217-223. https://doi.org/10.1080/15427609.2015.1071944

Stapleton, J. G., Phillips, K. G., Moynihan, M. M., Wiesen-Martin, D. R., \& Beaulieu, A. L. (2010). New Hampshire Endowment for Health Planning Grant Report: The Mental Health Needs of Children Exposed to Violence in Their Homes. Concord, NH: New Hampshire Coalition against Domestic and Sexual Violence.

Straus, M. A., \& Michel-Smith, Y. (2014). Mutuality, Severity, and Chronicity of Violence by Father-Only, Mother-Only, and Mutually Violent Parents as Reported by University Students in 15 Nations. Child Abuse \& Neglect, 38, 664-676.

https://doi.org/10.1016/j.chiabu.2013.10.004

Suzuki, S. L., Geffner, R., \& Bucky, S. F. (2008). The Experiences of Adults Exposed to Intimate Partner Violence as Children: an Exploratory Qualitative Study of Resilience and Protective Factors. Journal of Emotional Abuse, 8, 103-121. https://doi.org/10.1080/10926790801984523

Wheaton, B., \& Gotlib, I. H. (1997). Trajectories and Turning Points over the Life Course: Concepts and Themes. In I. H. Gotlib, \& B. Wheaton (Eds.), Stress and Adversity over the Life Course (pp. 1-26). New York: Cambridge University Press. https://doi.org/10.1017/CBO9780511527623.001

Widom, C. S., DuMont, K. A., \& Czaja, S. J. (2007). A Prospective Investigation of Major Depressive Disorder and Comorbidity in Abused and Neglected Children Grown Up. Archives of General Psychiatry, 64, 49-56. https://doi.org/10.1001/archpsyc.64.1.49

Wolfe, D. A., Crooks, C. V., Lee, V., McIntyre-Smith, A., \& Jaffe, P. G. (2003). The Effects of Children's Exposure to Domestic Violence: A Meta-Analysis and Critique. Clinical Child and Family Psychology Review, 6, 171-187. https://doi.org/10.1023/A:1024910416164

World Health Organization (2017). Violence against Women. Geneva: World Health Organization.

Yoshihama, M., Clum, K., Crampton, A., \& Gillespie, B. (2002). Measuring the Lifetime Experience of Domestic Violence: Application of the Life History Calendar Method. Violence and Victims, 17, 297-317. https://doi.org/10.1891/vivi.17.3.297.33663

Zeoli, A. M., Rivera, E. A., Sullivan, C. M., \& Kubiak, S. (2013). Post-Separation Abuse of Women and Their Children: Boundary-Setting and Family Court Utilization among Victimized Mothers. Journal of Family Violence, 28, 547-560.

https://doi.org/10.1007/s10896-013-9528-7 